\title{
Information Society and Knowledge Gap in The Third World - A Conceptual Approach -
}

\author{
Abdallah Tani Mohammed El Nadir, University of Mostaganem, Algeria
}

\section{Introduction}

Information Society, the term spread in the West and USA, primarily it served as a continuation of the theories that spawned the terms of the industrial society and postindustrial, as is evident from the "title" At the basis of the label technological optimism of capacity to resolve many social problems which are intractable by using the information, other than the descriptive, which codifies and inaugurates the objective spread of "computing" and "media" that interspersed with the social fabric as a whole. And often draws attention to focus on the Japanese experience, which provides an example of the information society in Japan, an ambitious program that aims to create and develop the social structure Computers distinct include production, distribution and transportation services and management, education and livelihoods, and this social structure - Computer permeate networks télé-computing (télé in Greek meaning away and dimension) so that people can through them to solve their own professional problems by direct contact, and there is a national policy in Japan for the creation and establishment of "industry knowledge" as well as projects to reform the country's social development, including the systems of rehabilitation workforce and of re-distribution, so that the community becomes in its Supreme stages " $j$ Masuda," who is one of the leaders of that program - to a consumer society and prosperous of high class, and then going to solve all personal problems - according to this belief - and its requirement of creativity and self-realization through the global use of planetary information, so they attaches a great hopes on the "globalization" and "internationalization" of the trends of new information - that is for "computing" the society and its global planetary "medias".

As Mr. Maan Nakkari (2) seen that the careful total evaluation of the revolution of new science and technology and the different dimensions of the revolution of computer and technology of information and their effects on human society as a whole and lts diverse communities (means the information gap), especially the developing societies, including the Arab countries - all that need a private and reflective attention, As can see researcher at Media fields AWATIF Abdel Rahman that the problem of developing countries is in the mis-choose of appropriate technology for their needs, resources and background of its civilization, the fact that impel us to discover an other important truth is that the responsibility lies primarily on the scientific institutions that contribute to making the decision to import technology (3) It is through these ideas manifested problem at hand: what extent the efficacy of new technologies of information and communication in addressing the problem of knowledge gap in the third world? . 


\section{Conceptual Network}

\section{The Phenomenon of Explosion of Information}

The more evolved human life, and complicated information accumulated, with an expanded use, and thus increasing our need for more information that helps us make good decisions. The information resource is not inexhaustible, and an indispensable element of any society and any individual.

From the early time the volume of information was increased, flowing from many sources, accompanied by a growing need to organize this information, and stored in ways that provide maximum speed of retrieval in any time and from anywhere. This chapter presents the importance of the information, and the problem of explosion of information, information society and its dominant in the second half of the twentieth century.

\section{Information Society}

The society of information have exited before the concept of information society was appeared, but some authors have different definitions, including the definition of Branscomb, where he knew that «the society that relates to the manufacture, collection, processing, storage and retrieval of information». Roenfeld indicated that «society which deals mostly with computers and satellite communications systems and global information networks») (4).

\section{The Concept of the Information Society}

The information society comes after several stages in the human history, and each stage marked its characteristics and advantages, from fishing technology, and agricultural technology, to the information technology, which painted the first features of the information society that distinct by, "focusing on processes that address the information, and the basic raw material it is information, which is being invested to generate knowledge, a new knowledge.

That basic materials are different in an other communities, where depleted due to consumption, whereas in the Information Society The information generated information, which makes the sources of the information society, renewable and inexhaustible, "which explains the importance of the information, and its status as the most important raw material at all, that what makes the new society depends on this resource, communication networks and computers, that societies are characterized by the presence of goods and information services were not present before, as well as it depends mainly on the "intellectual" technology, by giving more importance to the thought, the human mind with computers, communication, artificial intelligence and expert systems. Another definition given to the information society: If we want to know the information society, we must study several topics that will facilitate access to the nature of the information society must come from a universality introduction in order to generate some universal concepts and terms. Now information is the prime mover of all activities and operations which is the basis of reference upon which the decision-made and all the institutions focused on the acquisition of information sources, its conservation and retrieval it in time, the information revolution led the updated procedures for the spread of modern means of communication that has made an open society (5).

\section{Arab Information Society}

The Arab perspective Information give us a picture about the information and technology and their relationship with culture in the Arab community and we present briefly the perspective 
of the Arab Information, and the challenges of the Arab intellectual in the preparation of him self, so he can walk in the maze of the third millennium that soon after a brief period that the seekers of axioms and the forgotten, and so forth in the accumulation of information and updated, as it doubles every eighteen months. in order to faced this flood, it must overcoming the following challenges:

- Identify the current map of the Arab Thought and its main orientations -As Turki al-Hamad recommends to get out from its mental conceptual isolation in time and every where it is the isolation that reflected politically on its position toward events and its evaluation.

- Accommodate the cultural and social aspects of the informational variable, which is the main goal of our research now, and should beat the intellectual of government, who usually the government use the technical experts to form him, and that what makes his weakness.

- I promised to renew the knowledge, theory of literature to the theory of information, from a macro economy to a micro-biology, and from philosophy of science to artificial intelligence and Internet.

- The acquisition of communication skills and proficiency in "etiquette" of online dialogue (6).

\section{The Importance of Information}

Information has a vital role in individuals life and communities, it consists an indispensable element in any activity that we practice, it is such a raw materials in Scientific Research, and the key to make a the right decisions, and he who has the right information, at the right time, has the elements of power and control in that changing world based on science in all, with any improvisation or randomness.

Some go in its evaluation of the fundamental pillars of national output which are : material, energy, and information the last one occupy the first place in term of importance, but he went further, announcing the rates of growth of national economy linked directly proportional to the amount of information that are familiar, and many scientists of economy confirm that the situation is bad for the economies of most developing countries may get worse if they continued to neglect the information sector and if we realized that information is indispensable now in all aspects of activity, the task of follow-up information, and managed its production, has become almost impossible, and then the explosion of information became a real problem menacing humanity (7).

\section{The Problem of Information Explosion}

The term information explosion refer to the breadth of the field in which information is operated to include all areas of human activity, so the production of information was transformed to industry now with a large market such the oil markets and gold, what is spent on the production of information - at the international level - has more than what is spent on a lot of strategic commodities in the world (8). The problem of information explosion has been manifested such:

\section{The Huge Growth in the Volume of Intellectual Production}

Some believe that the annual growth rate of intellectual production ranges between $4 \%-8 \%$, so that we can offer an image of the root of this crisis by setting an example of a periodic on important Scientific journals in the field of chemistry in U S A, has issued this topic session 
in 1908, and completed a million search first after the thirty-one years old. and then spotted one million search the second of eighteen years, and made the third million search in seven years, and in general the amount of information is doubling every twelve years, the production volume has increased, published in the intellectual journals - the only one of many forms of publication - of about a hundred journal in 1800 to more than 70 thousand a patrol in the eighties (9).

\section{Dispersion of Intellectual Production}

The excessive specialization in the scientific topics has an evident impact on the emergence of new branches based on different sections, such a biomedical engineering, and biochemistry. There is another observation show that the researchers tend to study very narrow subjects, and the more researchers specialized, more the size of the production of intellectual publication become large, thus be difficult for the researcher to follow all this intellectual and knowledge production from its primary resources.

Statistics indicate that the annual production of information estimated the number of documents published up between 12-14 million documents, and that the number of people contributing to this production, by one way or another, ranges between 30-35 million periodicals, in addition to each year approximately 15 thousand new periodicals, The international production of books have reached about 600 thousand, an average of 1650 books a day, or 70 books per hour (10).

\section{Diversity of Information Resources and the Multiplicity of its Forms}

There are many resources of information, including periodicals, books, research reports, data, and the papers presented at seminars, conferences, theses, patents, and uniform standards, and standards, as well as the mini publishing, which means either re-registration of written texts in the form of books and periodicals in the miniature form, or recordings of new information in the form of a mini directly, such as micro film, microfiche, films, slides, tapes, disks, and others. The use of microfilm alone in the centers of media information reached between 95 $99.5 \%$ of the space required to save the information, boom in the production of information led also to the boom similar in the field of information storage and retrieval, and the computer was used in order to standardize the sizes of the documents copies after a period of suffering because of its varying in sizes, and forms, the cost of information storage has reduced by nearly $20 \%$ during the last fifteen years, and speed of retrieval information has increased by $10 \%$ per year.

Furthermore, there is a tremendous amount of information transmitted by means of mass media, the UNESCO statistics indicate that between 200-250 people per thousand of the working population receive the distribution of daily newspapers, as well as reception services, radio and television, and there are 30 countries in the world reached the saturation point in the field of newspapers, 38 countries have reached saturation point in the field of radio services, and 22 countries reached the saturation point in the field of television services. On the other hand there are in different world countries 116 nation libraries have about 160 million volumes, and there are nearly 120 agency news national and international working in the field of information and news, broadcast daily over a half million news and information, a quarter of at least video and audio recorded . 
Satellites provide also as large and diverse information that investigate into the development directly, without it no country could plan effectively for their programs of development. The danger of this problem is in the treatment of information as a commodity to sale and purchase, subject to the law of supply and demand, and this information is easily accessible to companies of the developed countries, and obscure the important information for the under developing countries, and is no doubt that the information is not a commodity like other material goods, but it is a good non-material, with a high value estimated on the basis of social and cultural standard norms of development, not based on the standards of profitability (11) .

\section{The Nature, Characteristics and Goals of The Information Society}

The concepts varied actually, cultures and interests, which led the World Summit on the Information Society agreed to unified the concept, of what the information society and the development of approaches to political and regulatory networks and services in various countries in the world. As the communicative culture is the most important pillars of the international community, the adoption of some important principles and necessary to address the substantive question of the establishment and development of communication and information society in the Arab world is becoming a necessity. You can find out the most important principles of this topic below.

* the need to provide a uniform awareness level all over the world countries, that was as a result of the new concepts associated with the globalization of the economy. * The need to adopt new strategies that are consistent in their directions and programmes with the development of communication and information society at the international level.

* The inevitability of integration and complexity of the different formula - structural, technological, and cultural, economic and social - in the development of community of communication and information, which requires a broad consultation in various fields among all the actors from the public and private sectors and from all components of civil society in general.

* The third world need to shift from just a consumer of globalization to actor in the information society in order to achieve comprehensive and the integrated a sustainable development.

* The need to invest this abundance of information which abounds in the third world in the global budget (12).

\section{Information Society and There Dominants}

Emerged as a result of what some call - information society - with a new facilities and specialized networks, during the last century a computer entered in a research centers and universities, and then spread in the areas of trade and industry, and became an effective tool to resolve a complex calculations. During the decade of that century an increased reliance on electronic computer in order to perform a business functions, and there is a need for action windows - central and exchange of information, and possible transfer of signal data communication. As a result of all this evolution in the data connection is the better use of telephone networks realize the transfer from analog signal to digital signals.

Through the seventies years, the progress continued in the field of Computer, and means of communication, has resulted the emergence of services, semiconductor, and technology, semiconductor materials to heat many of the transfer of information such as e-mail, and television services that allow retrieval of information such as telex, and video data, audio, 
video, and teleconferencing, this topic developments, houses related to the wired network (13). New concepts such as offices with a self-administered automated. All of this made us live in the information age, a child born in the house of Wired households with a computer is a child of the information society, while a child growing up in a house without a computer is a poor child in the information (14).

This indicates why the government insist on the important of information tools in the advanced industrial countries in order to dominate and managed the world, but only in a few of these countries due to its control over the information, and the means of production, processing, storage, retrieval, and this is done rapidly and on a grand scale, leading to make a few producers against many consumers, the elite control and the majority are oppressed, one group getting more and more richer and control the other, and all the rest of groups were becoming more and more poorer and be in dependence all the time (15).

\section{Information Society and Digital Gap Digital Gap}

The danger of the digital gap is in the possession of information and communication technologies form the modern and possessing the skills required to deal with, it can give a social and economic priority to those who possessed than those who are not, even they are states or organizations or citizens, may that preference mean for members the difference between poverty and prosperity and for States or communities the success to join in the new global economy or there isolation from it.

In the years 1970-1980, the major industrialized countries have legitimacy to help countries of the South in the evolution of communication in order to be exploited in the first place to strengthen management authoritarian in the South and to allow the machine propaganda and ideological political work, and in the early third millennium, this assistance before being given to individuals and women to deal with the information and knowledge, the size of the digital gap is that it requires a huge effort to reduce the art of the industrial countries has exceeded expectations, also calls for a new partnership around a common purpose, in the political, economic and social development in the north and south. by this way we can avoid the margin in a distinct minority, "is rich in information, or to put millions of people excluded from the cyber world to a society hungry for information (16).

\section{The Information Society through the Digital Gap}

The first of the foundations that will enable the third-world to use communication technologies and information technologies of communication and information an optimally used is by determining what the Third World want in this point, and what are its objectives in this area, in order to develop policies and plans and enact legislation to ensure the maintenance and the implementation of strategies. It is useful perhaps to stop at the potential future prospects of the Arab communities through the establishment of a society of communication and information. Information technologies was shattered the artificial barriers and it is possible the exchange of goods, services, and counseling among third world countries without the need for the real move, and most importantly, that develop a sense of being global citizens contributing to the enrichment of human civilization.

The terms of that lies in knowledge of the reality of that age and its intellectual, technical, cultural aspect, and problems, and to develop the policies resulting from conscious knowledge about international and Arab citizens reality to cope with the technological 
development and contributes to the enrichment of human culture. Although there are no specific perceptions about what will happen in the third world and in the world around: Results of rapid development and amazing communication technologies, but it could, based on the past and present experiences, to say that there are several options will be available to the citizen as part of human being as the ways of earning, living, investment, the sale, purchase, family life, workplace, methods of teaching and learning will change (17).

\section{The Era of Knowledge}

If the process of knowledge production depends on the large existence of information, and if the interpolation means of experimentation and the concrete more than anything else, the important observation is that social phenomena can not be summarized, as a natural phenomena, political activity for example is based on human being and how he can manage his affairs, so the intellectuals are asking the concept of management of knowledge for Humanitarian affairs, which depends on the cultural aspects and its effects on the human behavior, in other words it deals with social intelligence, which consists of a humanitarian deal with each other and participate in the management of its affairs by means of a humanitarian decent (18).

\section{Challenges of the Information Society Knowledge Society}

A report of the United Nations Educational, Scientific and Cultural Organization in 2005 entitled (from the information society to knowledge society), and it is stated under the title (could not reduce the knowledge societies into an information society) should not be for the emergence of a global information society, as a result of a new revolution technologies, to make us forget that it is only suitable way to realize a real community of knowledge, Thriving networks can not alone assess the knowledge bases. Because if the information is really a way to knowledge, that doesn't mean that information is the knowledge (19).

\section{The Characteristics of the Knowledge Society}

The knowledge societies characterized by the fact that knowledge is the most important components included in any work or activity, especially in relation to the economy, society and culture, and all other human activities that depended on the availability of a large amount of knowledge and information, in a knowledge society or a knowledge economy, the knowledge consists the most important products or raw materials. And the knowledge society is not a newly, it was, for example, fishermen share the knowledge for a long time on weather forecasting in the context of the communities in which they live, and are constantly adding more to this knowledge, which is part of the capital of these communities. What is very recently is that:

- with the modern technologies, it is no longer necessary to be in the same geographical location.

- The technology available currently has more possibilities to sharing knowledge, its conservation and its restoration.

- Knowledge has become the most important components of capital in this century, and the progress of any society has become primarily associated with the ability to use it.

\section{The Important Growing of The Knowledge Society and its Association with Society in Whole}

Every society is formed by a set of common concepts, globalization and information and communication technology has led to form a global community characterized by the common 
knowledge about all the world issues and its possibilities. The material resources and its own manufacturing processes (i.e., economic resources) were the basis of the economic development, while there were things as music, art, and mixing of cultures (i.e., cultural resources) are the factors that drove development in to the whole of community, and with the access of community to the stage of maturity the knowledge became available in the documents, the laws, written and unwritten rules, people's opinions, their beliefs, words they use in each language, and so on, as is the case of the absence of equitable distribution of material and economic resources, which created a sort of inequality within the society, that what hampered the sharing of knowledge and the development. And knowledge societies are aware of the importance of knowledge building, sharing and distribution of appropriate in the development of societies.

\section{The Knowledge Gap}

This theory was developed after observing the results of numerous researches indicated that the different public sectors have the same balanced access to information flowing from the modern means of communication .this theory based on the following hypothesis : "The fluency of information from the media within the social system to make category with the high socio-economic level, acquire this information faster than categories with the low socio- economic level, , and thus moving the knowledge gap between the two categories increased rather than decreased (20) (Tichnor, Donohu \& Olien1970). This hypothesis underlines that the groups with low socio-economic level do not remain poor in the information in general, but it is gaining relatively less information than in the groups with higher socio-economic level.

1- So many researches had confirmed the validity of such hypothesis in United States, Europe, Latin America, and the Middle East .... Noting that economic and social factors are the major determinant of the public acquisition of knowledge. It is also now apply (the theory of the knowledge gap) on the two main levels:

\section{The Individual Micro Level:}

The individual micro level and includes the acquisition of knowledge and the means of communication, which is depend on the following: individual differences, communication skills, cognitive ability, the level of interest, and other individual factors.

\section{The Macro Social Level}

Macro level includes the nature of the social structure and the variables associated with the society, such as: methods of diffusion and distribution of information, the available means of communication, the nature of social conflict, and the ownership of the media and means of financing and operation (. (Tichnor, Donohu \& Olien1970). Also made by the researcher Salman Rashid Salman that he does no doubt that the technological gap and the economic have created the so-called the countries of the center, which are economically and technologically developed countries and dominate the other countries, that represent the poor world, including the Arab countries to scientific and technological infrastructure and heavily indebted, the dependency between the center and the periphery transformed from political to economic dependency, but now the poor countries depend on the center in knowledge what increases the economic and political dependency of under developing countries and . This dependency has been exacerbated, especially in the field of information, as it is created and sent on onedirection, which is from the center to the periphery. 


\section{The Principle of Freedom In Knowledge Society}

1. The nature of knowledge is free and free of charge.

2. Knowledge must remain free for the benefit of society.

3. Knowledge must remain free of in order to achieve further development of this knowledge and its elaboration.

4. Should discuss the point of view which says that the liberation of

Knowledge or make them free will kill motivation.

Examples of groups that can grow to be among knowledge societies Individuals working in the same area

- Teachers who teach the same material.

- people loving the same band.

- Artists with convergent interests.

Individuals from different disciplines.

- Engineers who coordinate with the scientists worked on the same subject.

- Researchers from various fields who discuss the problem of scientific research.

- Mystics and clerics in their dialogue with scientists.

\section{Infrastructure}

Knowledge society requires a infrastructure includes the following:

1. Physical infrastructure, such as meeting rooms and discussion boards.

2. Technological infrastructure, such as techniques of information-sharing, mailing lists , electronic gates cyber (Internet-based), awiki pages, chat rooms and video conferencing (video conferencing), meetings, virtual default, development environments through collaboration, and distance learning (22).

\section{The Question of Individuality.}

"... The individual serves the group in the most case, what is always positive. To give source to a new hobby, associations, and groups against fans - culture, it is not against democracy --. One of the first results of the historical sociology of the media, prepared by the Robert Park, is that the minority groups that use different media, to defend both their identity and to help achieve their integration into the collective. Privacy partial that exhausted itself on countless microscopically sites that are not seen in the Internet and may not be utopia, but it realizes that it does not undermine the social changes in his speech after all, it is just mass media ..."(23).

\section{Conclusion}

In less than two decades the world has lived a comprehensive technological change in the economic, political and cultural fields. the winds of change were described by the information revolution, or the Second revolution after Industrial Revolution. The slogan of this revolution is the computer or electronic brain as it was represented in science fiction movies. This device was able to rearrange the activities of the political institutions, social, cultural, factories, communications, media processing, storage and retrieval of information. But with the advent of the information society and its manifestations on the Arab societies differences in individual and collective have emerged, and the change in Arab society from a behavioral standpoint, the behaviors of individuals and groups have changed, that was done in the communities of information and knowledge because there are communities which are 
still primitiv, what resulting in the world a digital and knowledge gap between major industrial countries and the countries of the Third World, including Arab countries, the major challenges of the information society reflected in individualism and e-democracy, there is a flexibility in the information access through the highways of information, the human being cyborgien, what means half human being deal with the machine in most of his time that reflected on his life and behaviors by adopting a new way of life, however, he lives in a society fueled by information, and his economy is based on the information, so will he profit from this style of living and use it in a good way and to his favor and to the favor of society and transforms information into knowledge and the ocean around it, or engaged in severe consequences and disadvantages as extravagance of his the effort, time and money?

The Moroccan researcher Yahya Yahyaoui has concluded that "the tensions between the enablers of information technology, communication, and to devote democrat access to knowledge can only be deepened and increased by the absence of democracy, the rejection of pluralism and the other opinions, and the dominance of the security obsession apprehended from the all-new, and the marginalization of scientific research, and to devote the values of elitism to take advantage of technological developments "(24). 


\section{References}

MAN Nakkari, informatics and society (post-industrial society and information society), i 1, Beirut, Lebanon, the Arab Cultural Center, 2001, p. 175-.177

AWATIF Abdul Rahman, the issues of media and cultural dependency in the Third World, $\mathrm{i}$

1, Cairo, Egypt, the Arab Thought House, 1997, p. 6.

Http://ar.wikipedia.org/wiki/ .27/07/2008. heure, 14: $00 \mathrm{~h}$

Http://ar.wikipedia.org/wiki/ 28/07/2008. heure, 12: 00 h.

Praise Turkish, Arab culture in the era of globalization, i 1, Dar Al-Saqi, Beirut, Lebanon, 1999 , p. 52.

Emad Hassan Makkawi, modern communication technology in the information age, i 1,

the Egyptian-Lebanese House Publishing, 2003, Cairo, p. 28 - p. 29

Farouk Abu Zeid, the collapse of the international information system of the bilateral control to the dominance of the pole 5 per Cairo Press news today, the first Tabau $0.1991, \mathrm{p} 13$.

Ahmed Badr, the entrance to the library and information science, i 1, Riyadh: Mars Publishing House, 1985 - p. 81-82.

Mohammed Fathi Abdel Hadi, Introduction to Information Science, i 1, Cairo: Egyptian Anglo Library, 1948, pp 19-22.

Sean McBride and others, and multiple voices one world, communication and society today villain, Report of the International Commission for the study of communication problems - Algeria: the national company of the publication and distribution, 1981 pp 326-327.

Tarek Mahmoud Abbas, the digital information society, i 1, the center of the original printing, publishing and distribution, Egypt, 2004, p. 110-.111

Op.cit, p. 32 / Emad Hassan Irons

Emad Hassan Makkawi, Ibid, p. 33

Hamdi Kandil, space communications, $\mathrm{m} \mathrm{1,} \mathrm{the} \mathrm{aunt} \mathrm{of} \mathrm{the} \mathrm{Egyptian} \mathrm{Book} \mathrm{Organization,}$ Cairo, 1985, p. 37.

Allain modoux, les défis de cybermonde, la fracture numérique peut conduire à la création ..., les presse de l'université laval, québec, canada, p209

Mohammed Fathi Abdel Hadi, information and information technology on the threshold of a new century, i 1, Cairo: Dar Lebanese Egyptian /, 2002, p. 55

Ghaleb Awad Alnoaash services to beneficiaries in libraries and information centers, i 1, Amman, Dar Al-Safa for publication and Altazaa /, 2000, p. 142.

Tarek Mahmoud Abbas, op.cit, p. 143.

Irons Imad Hassan, Leila Hussein Sayed, communication and contemporary theories, i 7, Dar Egyptian-Lebanese, Lebanon, 2008, pp 339-340.

Salman Rashid Salman, the strategic dimension of knowledge, i 1, the Gulf Research Center, United Arab Emirates, 2004, p. 152.

Http://ar.wikipedia.org/wiki/\% D9\% 85\%, 30/08/08. 18:00 h

ERIC MAIGRET, sociologie de la communication et des médias, Armand colin / paris, 2003, p266, 267.

Yahya Yahyaoui, in globalization, technology and culture - Introduction to Knowledge Technology -, i 1, Vanguard House, Beirut, Lebanon, 2002, p. 179.

Michel Mathieu CERIME, la «société de l'information» entre mythes et realités, Imprimé en Belgique.BRUXELLES, 2005. 